\title{
Phase II AIDS Malignancy Consortium (AMC) trial of topical halofuginone in AIDS-associated Kaposi's sarcoma (KS): clinical and biological effects using a novel intra-patient control design
}

\author{
Susan E Krown ${ }^{1 *}$, Barbara Fingleton ${ }^{2}$, Jeannette $Y$ Lee $^{3}$, Merrill J Egorin ${ }^{4}$, Henry B Koon ${ }^{5}$, \\ The AIDS Malignancy Consortium \\ From $12^{\text {th }}$ International Conference on Malignancies in AIDS and Other Acquired Immunodeficiencies \\ (ICMAOI) \\ Bethesda, MD, USA. 26-27 April, 2010
}

\section{Background}

KS is a disease of multifocal vascular proliferation. Matrix metalloproteinases (MMPs) and type I collagen play critical roles in angiogenesis and are potential targets. Halofuginone $\left(\right.$ Tempostatin $\left.^{\mathrm{Tx}}\right)$, a synthetic quinazolinone alkaloid derivative, induced anti-angiogenic, anti-metastatic and anti-proliferative effects in preclinical studies. It inhibits several essential stages of angiogenesis: endothelial cell proliferation, MMP2 expression, $\mathrm{BM}$ invasion, ECM deposition by newly formed vessels, synthesis of type I collagen during angiogenic sprouting, and bFGF-induced neovascularization. These data suggested that halofuginone might have activity in KS.

\section{Methods}

The AMC developed a novel trial design with a blinded intra-patient vehicle control. Halofuginone was supplied by Collgard Biopharmaceuticals Ltd (Atlanta, GA) to the NCI-DCTD under a CRADA as a $0.01 \% \mathrm{w} / \mathrm{w}$ ointment. Twelve KS lesions were divided into two groups of six, designated Group A and Group B. Tubes designated A and $\mathrm{B}$ containing either halofuginone or matching placebo ointment were supplied in a blinded fashion. Ointment A was applied to Group A lesions and ointment B to Group $B$ lesions twice daily. Lesion response was assessed every 4 weeks for Group A and Group B lesions individually, and global response assessed both treated and untreated

\footnotetext{
*Correspondence: krowns@mskcc.org

'Department of Medicine, Memorial Sloan-Kettering Cancer Center, New York, NY, USA

Full list of author information is available at the end of the article
}

disease. Tumor biopsies obtained at baseline and from both Group A and B lesions during treatment were studied for expression of type I collagen by ISH and of MMP2 and VEGF by IHC. A patient subset had blood sampling after 8 weeks to evaluate systemic absorption.

\section{Results}

Twenty-three patients were treated. Median CD4 count was 322 (2-693); 68\% had undetectable HIV RNA. Treatment was well tolerated. Of 14 patients who completed 12 weeks of treatment, $26 \%$ (95\% CI, 10\%-48\%) showed partial response in halofuginone-treated lesions and $17 \%$ in placebo-treated lesions (95\% CI, 5\%-39\%), ( $\mathrm{P}=0.689$ ). Global response was 30\% (95\% CI, 13\%-53\%). None of 10 subjects showed detectable blood levels. Type 1 collagen message decreased significantly in halofuginonetreated lesions at week 4 , whereas vehicle-treated lesions showed no change. VEGF protein expression decreased significantly in vehicle-treated lesions at week 4 , whereas halofuginone-treated lesions showed no change. There were no differences in levels of MMP2 or VEGF protein between halofuginone- and vehicle-treated lesions. No changes in HIV RNA levels or CD4 counts were observed.

\section{Conclusion}

Although topical halofuginone appears ineffective for KS treatment, this study presents a novel design that could be applied to future studies using the patient as his own control to test a topical, non-absorbed agent. 


\section{Acknowledgements}

This work was supported by UO1 CA121947.

This article has been published as part of Infectious Agents and Cancer Volume 5 Supplement 1, 2010: Proceedings of the $12^{\text {th }}$ International Conference on Malignancies in AIDS and Other Acquired

Immunodeficiencies (ICMAOI). The full contents of the supplement are available online at http://www.biomedcentral.com/1750-9378/5?issue=S1.

\section{Author details}

'Department of Medicine, Memorial Sloan-Kettering Cancer Center, New York, NY, USA. ${ }^{2}$ Department of Cancer Biology, Vanderbilt-Ingram Cancer Center, Nashville, TN, USA. ${ }^{3}$ Department of Biostatistics, University of Arkansas Medical School, Little Rock, AR, USA. ${ }^{4}$ Departments of Medicine and Pharmacology, University of Pittsburgh Cancer Institute, Pittsburgh, PA, USA.

IIreland Cancer Center, Case Western Reserve University, Cleveland, OH, USA.

Published: 11 October 2010

doi:10.1186/1750-9378-5-S1-A62

Cite this article as: Krown et al: Phase II AIDS Malignancy Consortium (AMC) trial of topical halofuginone in AIDS-associated Kaposi's sarcoma (KS): clinical and biological effects using a novel intra-patient control design. Infectious Agents and Cancer 2010 5(Suppl 1):A62.

\section{Submit your next manuscript to BioMed Central} and take full advantage of:

- Convenient online submission

- Thorough peer review

- No space constraints or color figure charges

- Immediate publication on acceptance

- Inclusion in PubMed, CAS, Scopus and Google Scholar

- Research which is freely available for redistribution

Submit your manuscript at www.biomedcentral.com/submit 